\title{
Current Options for Treatment of Glaucoma in Pediatrics
}

\section{Fahad I Al-Saikhan}

Prince Sattam Bin Abdulaziz University, Riyadh 11942, Saudi Arabia

*Corresponding author: Fahad I Al-Saikhan, Vice Dean, Academic Affairs, Prince Sattam Bin Abdulaziz University, College of Pharmacy, Pharmacy Practice, P.O. Box 173, College of Pharmacy Pharmacy Practice, Al-Kharj, Riyadh 11942, Saudi Arabia, Tel: +966115886074; E-mail: fsaikhan@hotmail.com

Rec date: April 17, 2015 Acc date: June 20, 2015 Pub date: June 25, 2015

Copyright: (C) 2015 Al-Saikhan FI. This is an open-access article distributed under the terms of the Creative Commons Attribution License, which permits unrestricted use, distribution, and reproduction in any medium, provided the original author and source are credited.

\begin{abstract}
Introduction: The treatment of pediatric glaucoma is normally complicated in this population owing to the visual immaturity of pediatric patients. Its basic pathophysiology shows an abnormally elevated intraocular pressure that causes the production of optic nerve damage and the consequent visual loss in infants and toddlers. Various and current treatments of pediatric glaucoma have been explored in this paper. These include; surgical treatments, Latanoprost, alpha-2-selective agonists, levobetaxolol, brinzolamide, topical versus oral carbonic anhydrase inhibitor therapy, dorzolamide, trabeculotomy-trabeculectomy with releasable satures, antimetabolites, and cyclocryotherapy.
\end{abstract}

Methodology: The article carries out a literature review that focuses on current studies regarding pediatric glaucoma. A cross-sectional study on the most recent established and verified researches on the treatments studied has been analyzed and discussed. 25 literatures were chosen depending on their year of publication, giving an emphasis on studies done four to five years ago.

Findings: Most of these treatments focus on reducing fluid production and reduction of intraocular pressure. Medical treatments are preferred in relation to surgical ones and treatments such as Latanoplast, brimonidine, brinzolamide, Levabetaxolol, dorzolamide, and antimetabolite and releasable rise of surgery filtration have been proven safe and effective depending on the type of pediatric glaucoma.

Conclusion: It is notable that, the success of the current treatments of pediatric glaucoma depends largely on early diagnosis and effective and adequate control of IOP. The specific treatment is determined by nature and type of pediatric glaucoma present and in most cases, both medical and surgical treatments are preferable.

Keywords: Glaucoma; Trabeculotomy-trabeculectomy; Infantile; Juvenile; Pediatric; Aphakic; Carbonic anhydrase inhibitors; MMC; $5 \mathrm{FU}$

\section{Introduction}

Pediatric glaucoma is an elevation in intraocular pressure that is incompatible with the supposed health of the optic nerve and retina in children (Figure 1) [1-7]. The condition develops once there is a compromised drainage of aqueous from the anterior chamber, which revitalizes the development of a new anomalous steady state with an intolerable or improper high intraocular pressure. Wright and Biglan indicate that the treatment of pediatric glaucoma is considerably complicated by visual immaturity of this population. Childhood glaucoma is classified into primary infantile (open angle), juvenile glaucoma, and secondary glaucoma based on its diversity and origins $[7,8]$. According to Netland, primary glaucoma often has a genetic origin and is caused by an intrinsic disease of the aqueous hemorrhage mechanism while glaucoma of secondary origin is ocular disease, drug, and injury as well as systemic disease [9]. Secondary glaucoma types are classified into angle anomaly, lens-iris diaphragm abnormalities, aphakic glaucoma, eveitis, tumors, trauma, and drug depending on the cause. Wright indicates that primary infantile glaucoma occurs commonly in 1 out of 10,000 live births in the US, 1 out 12,500 in Western Europe, 1 out of 22,000 in Northern Ireland, and more common in Saudi Arabia with reported incidents of 1 out of 2500 live births [7]. Pediatric Glaucoma in the US is more common in males than females while it is the contrary in Japan.

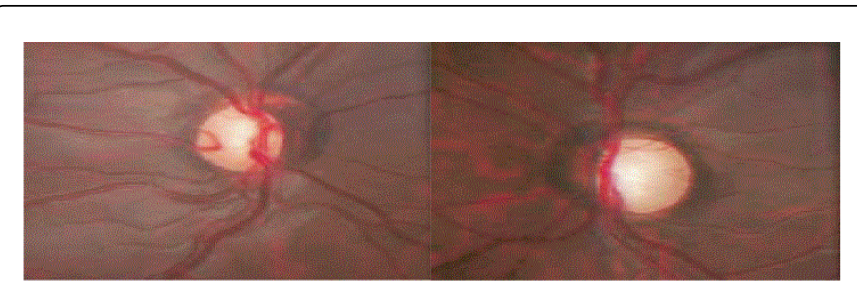

Figure 1: Advanced glaucomatous atrophy of this patient with near total rim loss O.S [15].

Olitsky and Nelson note that, both primary and secondary pediatric glaucoma can be linked to systemic conditions, and thus, an ophthalmologist ought to accurately interpret symptoms inherent in the eye in order to have clues for classification and diagnosis glaucoma and the associated system disease [10]. The onset of signs and symptoms occur before 1 year of age in $86 \%$ of affected children in the US and at birth in $40 \%$ of the population [7]. Pediatric glaucoma has varying treatment strategies and examination techniques distinct from those of adult patients. Treatments based on pharmacology, genetic, and technological advancement and the current diagnosis methods raise considerable hope of preventing visual impairment caused by the disease in children. Pediatric glaucoma signs vary largely among 
children depending on the severity of the IOP (Intraocular Pressure) rise, suddenness, and the age of the child. Clinical studies indicate common signs such as corneal edema, megalo-cornea, buphthalmos, optic nerve cuping, conjunctival injection, anisometropia, myopia, strabismus, and amblyopia. At the first year of life, glaucoma is normally supposed owing to the symptoms that are associated with secondary corneal changes. Equally, children who are considerably older are identified with the disease through the loss of vision caused by chronic glaucoma as well as signs of vomiting and pain associated with acute glaucoma. Similarly, the elevation of IOP is needed to ascertain the presence of pediatric glaucoma as the range of normal IOP in childhood approximates the normal adult range, and it is rare to have measurements greater than $22 \mathrm{~mm} \mathrm{HG}$ or below $10 \mathrm{~mm} \mathrm{Hg}$, and these measurements are essential in the management of children with glaucoma [10]. In infantile glaucoma, the iris indicates a more anterior insertion than one of a normal infant, showing altered translucency of the angle face yielding a unique ciliary body band, sclera spur, and trabecular mesh. Furthermore, corneal opacification and swelling are common signs heralding glaucoma in infants. Children with pediatric glaucoma can also be seen to withdraw from light, burying their heads to prevent exposure to light as well as rubbing of eye. This study reviews the current and up to date standards in the treatment of glaucoma in the pediatric population, focusing on fervently on ongoing researches on medications used in pediatric patients, the current guidelines of treatment, and a provision of recommendatory effective medication, based on the study.

\section{Review of Literature}

Studies indicate that the treatment of pediatric glaucoma varies depending on the type of glaucoma that is present even though medical surgery and therapy are needed in most cases $[11,12]$. According to Wright, primary infantile glaucoma is usually treated surgically, although medications have a definite role as adjuvant therapy, and, rarely, as the sole form of intervention [7]. Enyedi and Freedman study proposes Latanoprost as a treatment for pediatric glaucoma. The study indicates that Latanoprost is a prostaglandin F2 $\alpha$ analog, which decreases IOP by $20-40 \%$ with ocular hypertension in adults or with open-angle glaucoma [12]. According to Enyedi and Freedman, juvenile-onset and older children with open-angle glaucoma showed significant effects of ocular hypotensive when treated latanoprost [12]. Similarly, Black et al, study endeavors to examine the effectiveness of latanoprost in the treatment of pediatric glaucoma [2]. Their study focuses on assessing the lowering effect of IOP when using Latanoplast and its safety in children, exposing a total of 115 children with pediatric glaucoma for a period of 1 month while recording any side-effect information. Black et al. found out that out of the 115 children participants, 63 of them had IOP data that could be interpreted and side effects were mild, confirming the safety of using the drug in pediatric glaucoma [2]. Accordingly, Black et al. indicate that latanoprost has an IOP lowering ability in juvenile and old children with open-angle glaucoma and a small percentage of those with aphakic glaucoma [2]. Equally, Arthur and Cantor explore the effect of alpha-agonists in the treatment of glaucoma [1]. The study indicates that currently alpha-2-selective agonists have been used frequently in the treatment of glaucoma particularly brimonidine with a preference of brimonidine-purite formulations over BAC (brimonidine-benzalkonium chloride). According to Arthur and Cantor, brimonidine is normally effectual when it is used with betablocker, and has shown efficacy and better tolerability [1]
Whitson et al. study examines the efficacy of levobetaxolol and brinzolamide in the treatment of pediatric glaucomas, carrying out a randomized clinical trial in pediatric patients under the age of 6 in focus of IOP elevation [6]. The stud dosed pediatric patients twice a day with $1 \%$ of brinzolamide suspension and $0.5 \%$ of levobetaxolol for 78 pediatric glaucoma patients. Whitson et al. study found out that those patients who were randomized to brinzolamide and had no IOP lowering therapy had an IOP mean change ranging from $-4.1 \mathrm{~mm} \mathrm{Hg}$ to $-5.0 \mathrm{~mm} \mathrm{Hg}$. On the other hand, the patients under levobetaxolol indicated a mean change from $-1.8 \mathrm{~mm} \mathrm{Hg}$ to $-2.9 \mathrm{~mm} \mathrm{Hg}$ [6]. In implication, Whitson et al. concluded that brinzolamide was more effective in treating pediatric glaucomas that are associated with ocular abnormalities or that is systemic, but was less efficacious for primary congenital glaucoma [6]. Equally, Levabetaxolol was more effective in treating primary congenital glaucoma, and both drugs had nonserious adverse effects. Moreover, Pertellos, Buckley and Freedman carried out a study to examine the effectiveness of topical versus oral carbonic anhydrase inhibitor therapy for pediatric glaucoma, focusing on the hypotensive effective of diamox (oral acetazolamide) and trusopt (topical dorzolamide) in pediatric glaucoma patients [13]. The study used an average dosage of $9.9 \pm 1.8 \mathrm{mg} / \mathrm{kg} /$ day of acetazolamide and $12.2 \pm 19.7 \mathrm{mg} / \mathrm{kg} /$ day of dorzolamide [13]. The results indicated that all eyes studied showed that IOP mean decreased to $18.5 \pm 4.3$ $\mathrm{mm} \mathrm{Hg}$ when acetazolamide is used while there was an increase of IOP when switched to dorzolamide by $3.7 \pm 2.5 \mathrm{~mm} \mathrm{Hg}$. The study concluded that dorzolamide caused a considerable reduction of IOP in the studied population and as such, was well tolerated by glaucoma patients [13].

Nevertheless, Low, Hamada and Nischal evaluate childhood filtration surgery when using 5-fluoruracil in bleb needling, antimetabolite, and releasable sutures in the treatment and refractory of pediatric glaucomas [14] (Figure 2). Low et al. study reviews childhood glaucoma patients performing a combination of trabeculotomy-trabeculectomy with releasable satures, antimetabolites, and bleb modification [14]. The study found out that antimetabolite and releasable rise of surgery filtration emerged to provide favorable results in treating refractory primary pediatric glaucomas. In the treatment, Low et al. indicate that no major threatening complications were noticeable and as such, bleb-related infections and cystic avascular blebs did not develop in any of the eyes examined [14]. Nonetheless, Sowka suggest that therapeutic treatment options are able to treat juvenile open-angle glaucoma [15]. Biglan propose that when treating glaucoma in children, it is essential to remove congenital cataracts after 3 to 4 weeks of age and the treatment of amblyopia is significant in controlling pediatric glaucoma [8]. Furthermore, the study indicates that new technologies such as measurement of corneal thickness and optical coherence tomography have played a significant role in evaluating pediatric glaucoma cases. Wagle, Freedman, Buckley, Davis and Biglan carry out a research to assess the rate of success of cyclocryotherapy for the treatment of refractory pediatric glaucoma [16]. The research performed a cyclocryotherapy on pediatric glaucoma patients who were resistant to surgical and maximal medical interventions [16]. According to Wagle et al. study, cyclocryotherapy was a successful and reasonable method of lowering IOP, especially in refractory glaucoma [16]. The study indicates that cyclocrytherapy was not effective in the treatment of patients with aniridia since they showed an increased rate of phthisis when subjected to cyclocryotherapy. 


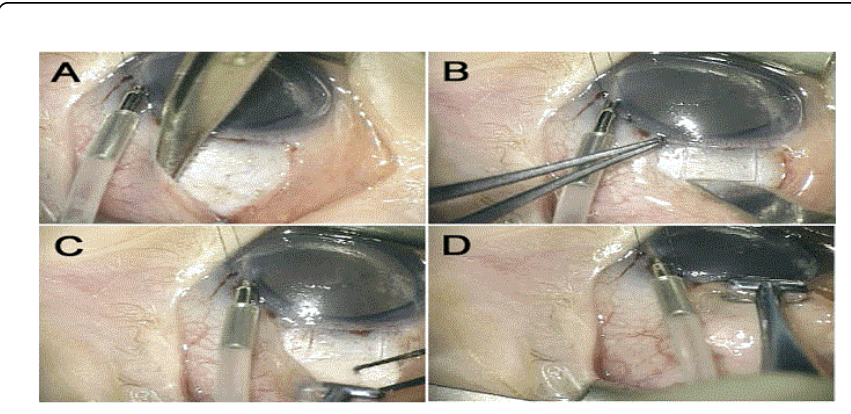

Figure 2: (A) Fornix-based conjunctival flap. (B) Scleral flap (4-3 $\mathrm{mm}$ ) scored out. (C) Mitomycin-C (MMC) 0.2 to $0.4 \mathrm{mg} / \mathrm{mL}$ or $5-$ fluorouracil (5FU) $25 \mathrm{mg} / \mathrm{mL}$ (four to six soaked pledgets) inserted into posterior pocket for 2 to 4 minutes. (D) Conjunctiva drawn toward limbus for antimetabolite exposure to scleral flap site [15].

Plager et al. carry out a study to assess the safety profile and IOP elevation when using timolol maleate ophthalmic gel-forming solution and betaxolol hydrochrolide ophthalmic suspension in pediatric patients below age of 6 [16]. According to the study, the use of betaxolol ophthalmic suspension was tolerated well making significant reductions in IOP mean in most of the pediatric glaucoma patients [16]. Souza, Tran, Loman, Law, Coleman and Caprioli carries a study to assess the long-term effectiveness of ahmed glaucoma valve implantation in treating glaucomas focusing on its implication on IOP decrease on glaucoma patients [17]. According to the study, about 50\% of AGV implantations were successful in a period of five years. Flemmons, Hsiao, Dzau, Asrani, Jones, and Freedman research proposes home tonometry in the treatment of glaucoma using iCare rebound tonometry in the record of of IOP in children [17]. Flemmons et al. found out that the use of home tonometry was reliable particular when using iCare rebound tonometry, offering information in IOP that was valuable for management of pediatric glaucoma.

\section{Discussion}

Various treatment options have been suggested by various studies in the treatment of pediatric glaucoma [1,3-5]. As an adjunctive therapy, latanoprost is tolerated with good IOP response, and although the response rate is low in the pediatric population, in those that do respond it is very effective and offers good 24-hour control. According to Netland, the frequency of these side effects in children on long-term therapy is not well known [9]. It is also noted in the studies that timolol has been tested as an additional medication in uncontrolled pediatric glaucoma. As in adults, systemic levels of timolol can be found in pediatric patients after topical dosing, but at much higher levels and much of the plasma level increase can be explained by the much smaller volume of distribution in children as compared to adults. Furthermore, various studies indicate that oral carbonic anhydrase inhibitor administration can cause growth retardation and metabolic acidosis [9]. Moreover, a study of children between age 3 and 12 showed an effective lowering of IOP in pediatric glaucoma when comparing the use of systemic administration of topical dorzolamide and acetazolamide.

In the use of cholinergic drugs, they were the first medical treatment for glaucoma but are now seldom used for pediatric patients. Topical use of both pilocarpine and carbochol can be associated with cholinergic side effects, including diarrhea, gastrointestinal cramping, hypotension, headaches, salivation, syncope, and sweating [4]. The degree to which side effects are experiences is highly dependent on systemic absorption, which can be greater in pediatric patients. Since the majority of pediatric glaucomas result from structural and developed mental abnormalities of the angle and associated structures, these drugs may be less effective in lowering IOP. Furthermore, pilocarpine has been used to a limited degree in pediatric patients, and it may be used for induction of miosis pre and postoperatively for surgical goniotomy. Equally, long acting anticholinesterases such as echothiophate iodide are used mostly for the treatment of accommodative esotropia. Netland indicates that, since the agents are of poor availability, with no advantages over pilocarpine and with more serious side effects, they are seldom used for glaucoma therapy [9].

Notably, based on the study, epinephrine and dipivefrin nonspecific adrenergic agonists, are rarely used in pediatric patients, since, when considered for medical therapy, systemic side effects may limit their use in this population. Various researchers have studied the use of brimonidine, an alpha-2-selective agonist in the treatment of pediatric populations. Brimonidine has shown a slight decrease in IOP with a high rate of central nervous system depression while in other studies, side effects were sufficient to merit discontinuation of the therapy [5]. Conversely, medical treatments of pediatric glaucoma could include oral and topical carbonic anhydrase inhibitors, adrenergic agents, prostaglandins, and miotics. Often, oral carbonic anhydrase inhibitors are used to lower intraocular pressure in an attempt to clear the cornea for goniotomy surgery. According to Garg glaucoma valves can be useful as an alternative in the treatment of the pediatric glaucoma, in particular those cases refractory to treatment [18]. Garg indicates that it is not easy, however, to find pediatric valves according to the eye size in the childhood [18]. The amhed valve has been reported with a rate of success from 44 to $95 \%$ in the pediatric glaucoma. In refractory cases with multiple surgical procedures, and with poor control of the intraocular pressure even with medication, some eyes keeping some residual visual acuity can be treated with cyclocryotherapy.

\section{Conclusion and Recommendations}

For childhood glaucomas associated with a relatively poor surgical outcome, such as secondary glaucoma associated with aphakia, a medication trial is frequently warranted prior to surgical treatment. Medical therapy is also valuable postoperatively in controlling glaucoma in children in whom surgery is only moderately successful. Furthermore, physicians should be aware of the potential side effects of using the various available treatments since the pediatric population is a risky age group to deal with. Topical carbonic anhydrase inhibitors are both effective and save adjunctive agents in the treatment of pediatric glaucoma. Physicians need to be wary when using topical $\beta$ blockers during the neonatal period and in premature infants since there is a definite risk of bronchospasm and bradycardia. Furthermore, beta-blockers should not be used in infants or children with a history of reactive airway disease. In the treatment of pediatric glaucoma, the consultation with the patient's pediatrician and pulmonologist or cardiologist may be worthwhile if surgical or other medical options are limited. Parasympathomimetics and carbon anhydrase inhibitors have also been used systematically. In addition, side effects noted in newborns treated with glaucoma medications provide help in choosing treatment in late stages of pregnancy. 
Citation: Al-Saikhan FI (2015) Current Options for Treatment of Glaucoma in Pediatrics. Gen Med (Los Angel) 3: 1000189. doi: 10.4172/2327-5146.1000189

Page 4 of 4

\section{References}

1. Arthur S, Cantor LB (2011) Update on the role of alpha-agonists in glaucoma management. Exp Eye Res 93: 271-283.

2. Black AC, Jones S, Yanovitch TL, Enyedi LB, Stinnett SS, et al. (2009) Latanoprost in pediatric glaucoma--pediatric exposure over a decade. J AAPOS 13: 558-562.

3. Giaconi JA, Law SK, Coleman AL, Caprioli J (2010) Pearls of glaucoma management. New York: Springer.

4. Harley RD, Nelson LB, Olitsky SE (2005) Harleys pediatric ophthalmology. Maryland: Lippincott Williams \& Wilkins.

5. Weinreb RN, Liebmann J (2010) Medical treatment of glaucoma. Amsterdam: Kugler Publications.

6. Whitson JT, Roarty JD, Vijaya L, Robin AL, Gross RD, et al. (2008) Efficacy of brinzolamide and levobetaxolol in pediatric glaucomas: a randomized clinical trial. J AAPOS 12: 239-246.

7. Wright KW (2003) Pediatric ophthalmology and strabismus. New York: Springer.

8. Biglan AW (2006) Glaucoma in children: are we making progress? J AAPOS 10: 7-21.

9. Netland PA (2008) Glaucoma medical therapy: Principles and management. New York: Oxford University Press.
10. Olitsky SE, Nelson LB (2012) Pediatric clinical ophthalmology. London: Manson Publishing.

11. Khitri MR, Mills MD, Ying GS, Davidson SL, Quinn GE (2012) Visual acuity outcomes in pediatric glaucomas. J AAPOS 16: 376-381.

12. Enyedi LB, Freedman SF (2002) Latanoprost for the treatment of pediatric glaucoma. Surv Ophthalmol 47 Suppl 1: S129-132.

13. Portellos M, Buckley EG, Freedman SF (1998) Topical versus oral carbonic anhydrase inhibitor therapy for pediatric glaucoma. J AAPOS 2: 43-47.

14. Low S, Hamada S, Nischal KK (2008) Antimetabolite and releasable suture augmented filtration surgery in refractory pediatric glaucomas. J AAPOS 12: 166-172.

15. Sowka J (2008) Advanced juvenile open-angle glaucoma in an 8-year-old Haitian girl. Optometry 79: 126-132.

16. Wagle NS, Freedman SF, Buckley EG, Davis JS, Biglan AW (1998) Longterm outcome of cyclocryotherapy for refractory pediatric glaucoma. Ophthalmology 105: 1921-1926.

17. Souza C, Tran DH, Loman J, Law SK, Coleman AL, et al. (2007) Longterm outcomes of Ahmed glaucoma valve implantation in refractory glaucomas. Am J Ophthalmol 144: 893-900.

18. Garg A (2011) Surgical techniques in ophthalmology: Pediatric ophthalmic surgery. New Delhi: JP Medical. 